\title{
Australian empirical study into genetic discrimination
}

\begin{abstract}
Margaret F. Otlowski, LLB (Hons) (Tas), PhD (Tas) ${ }^{1}$, Sandra D. Taylor, BSocStud (Sydney), PhD (Tas) ${ }^{2}$, and Kristine K. Barlow-Stewart, BSc (Sydney), PhD (NSW) ${ }^{3}$

This paper outlines a major empirical study that is being undertaken by an interdisciplinary team into genetic discrimination in Australia. The 3-year study will examine the nature and extent of this newly emerging phenomenon across the perspectives of consumers, third parties, and the legal system and will analyze its social and legal dimensions. Although the project is confined to Australia, it is expected that the outcomes will have significance for the wider research community as this is the most substantial study of its kind to be undertaken to date into genetic discrimination. Genet Med 2002:4(5):392-395.
\end{abstract}

Key Words: genetic discrimination, genetic risk, antidiscrimination legislation, psychosocial factors, social justice

A team of Australian researchers will be undertaking a nationwide empirical study during the next 3 years (2002-2004) into the newly emerging phenomenon of genetic discrimination. The study aims to investigate the nature and extent of genetic discrimination in Australia across three key perspectives: consumers, third parties (in particular insurers and employers), and the legal system. Furthermore, the study aims to examine the social and legal implications of genetic discrimination, with a view to making recommendations for use in the Australian legal and policy context.

Reflecting the interdisciplinary nature of the study, the research team comprises Associate Professor Margaret Otlowski, Faculty of Law, University of Tasmania, as team leader and Chief Investigator; Dr. Sandy Taylor, School of Social Work and Social Policy, University of Queensland as Chief Investigator, and Dr. Kristine Barlow-Stewart, Director, NSW Genetics Education Program as Partner Investigator. Drs. Sue Treloar and Mark Stranger are Senior Research Fellows with the project. The study will also be supported by an "Expert Reference Group" which will be available for consultation and discussion throughout the project. This group is composed of leading Australian experts across a range of disciplines including law, sociology, ethics, and clinical and laboratory genetics as well as consumer and industry representatives. Furthermore, Dr. Paul Billings, a pioneer of empirical research into the phenomenon of genetic discrimination in the United States, ${ }^{1}$ has agreed to act as international consultant for the project. The study is being funded by the Australian Research Council under its Discovery Grants scheme.

${ }^{1}$ Faculty of Law, University of Tasmania, Tasmania, Australia; ${ }^{2}$ School of Social Work and Social Policy, University of Queensland, St. Lucia, Australia; and ${ }^{3}$ NSW Genetics Education Program, Royal North Shore Hospital, Sydney, NSW, Australia.

Margaret F. Otlowski, LLB (Hons) (Tas) PhD (Tas), GPO Box 252-89, University of Tasmania, Hobart 7001, Australia.

DOI: 10.1097/01.GIM.0000029070.10807.44

\section{Background to the study and the limitations of existing Australian empirical data}

Reports of genetic discrimination have been documented in overseas jurisdictions since the early 1990s, including the United States ${ }^{1-3}$ and the United Kingdom, ${ }^{4}$ but it is only in more recent years that evidence has been emerging that genetic discrimination is also occurring in Australia. ${ }^{5-7}$ Following the first documented case study of genetic discrimination in Australia by Dr. Sandy Taylor in 1998, ${ }^{5}$ two further Australianbased studies undertaken by Dr. Kristine Barlow Stewart and David Keays have identified a total of 48 reported cases of genetic discrimination, primarily in the insurance and employment contexts. ${ }^{6,7}$ As accounts of genetic discrimination in Australia have come to light, interest in this newly emerging phenomenon, and concern about its implications for individuals affected, have been increasing. This growing level of concern is highlighted in the Australian Federal Government's decision to establish a major national inquiry to examine protection of human genetic information, a strong focus of which is on genetic discrimination. ${ }^{8}$

The wide-ranging consequences of genetic discrimination, both for the individual concerned and society as a whole, have been outlined in a growing body of literature on the subject, ${ }^{1,6,9-11}$ and genetic discrimination has been recognized internationally as a human rights issue which carries significant social, legal, and policy implications. ${ }^{10-12}$ Discrimination against individuals on the basis of genetic factors has the potential to generate significant social, health, and economic burdens for society as it diminishes the opportunities of genetically at-risk individuals in a range of contexts (for example, insurance, employment) and for some, may also impact upon potentially helpful engagement with preventive genetic medicine. While there appears to be a growing acceptance across a number of jurisdictions, including Australia, that reform initiatives are required to tackle the problem of genetic discrimination, there is less agreement about what form such reform 
measures should take. In developing and later evaluating reform initiatives in this area, it is clearly an advantage to be able to draw on reliable empirical data documenting the nature and extent of the problem.

While some empirical data are available to support the claim that genetic discrimination is occurring in Australia, research undertaken to date has been limited, both in its scope and design. There has, as yet, been no comprehensive and coordinated empirical research about the nature and extent of genetic discrimination across Australia. More significantly, the studies undertaken to date rely predominantly on unverified and, in many instances, anonymous accounts of individuals' subjective impressions of whether they received inequitable treatment from third parties such as employers or insurers. Although new initiatives are now being undertaken within the insurance industry in this regard, there has also been a general absence of systematic documentation and research into current third-party policies and practices within the Australian context to date, by which responses to issues associated with the genetic profiles of individuals are determined. Because of such limitations, studies of genetic discrimination to date should be viewed with caution. ${ }^{13}$ While they establish that individuals may believe that that they have been discriminated against on the basis of genetic factors, they leave little scope for objective assessment of the alleged discrimination: whether it was without legal justification and therefore unlawful, or whether it may have been legally justified pursuant to the exemptions that both insurers and employers have from disability discrimination. ${ }^{14}$

While the legal status of the conduct is a very important consideration (and therefore also the ability in a given case to establish whether or not the discrimination was legally justified), from a social and policy perspective, all forms of genetic discrimination are material, irrespective of whether or not they are unlawful. Moreover, given the growing dissatisfaction with the present laws, which permit third parties to discriminate on genetic grounds in some circumstances, there are wider reform issues that also must be addressed. For this reason, and reflecting the interdisciplinary nature of this empirical research, the research project described here will extend beyond the focus of whether or not genetic discrimination is unlawful.

\section{Overview of the project}

This study seeks to address the gaps in the existing empirical data. It will be the first Australian study to undertake nationwide empirical research into the phenomenon of genetic discrimination. The aims of this project will be pursued through a triangulated study design comprising three discrete projects: research with consumers; research with selected third-party sectors, namely insurers and employers; and research within the legal system. This comprehensive and integrated design, targeting not only the consumers but also third-party groups to explore the basis of decision-making in this area and analyzing the mechanisms through which such cases have been determined, will provide key knowledge about current Australian policy and practice with regard to this issue. Furthermore, the project makes an important advance on existing research by seeking to verify and elucidate consumer experiences of genetic discrimination with relevant third parties, both on an individual basis with explicit permission of voluntary respondents, as well as through the construction and analysis of case studies.

\section{Consumer study}

Comprehensive quantitative and qualitative data from consumers will be collected through focus groups, in-depth interviews, and a national survey. The research design is based on criterion sampling, with eligibility to participate based on specified criteria related to established genetic risk or family history of genetic disease; it is anticipated that total numbers of consumers contributing data to the project across Australia will be approximately 2000. Recruitment of subjects will be sought through open pathways to consumers (e.g., web-based access), genetic support groups, and clinical genetic services. Qualitative data will be generated from in-depth interviews and/or focus groups to establish greater conceptual understanding of the definition, dimensions, and experiences of genetic discrimination from consumer perspectives. This initial research will also inform the development of a national survey which will seek comprehensive information with regard to types and extent of perceived discriminatory experiences and the circumstances in which these have occurred, as well as perceived impacts, barriers to redress, and outcomes for consumers. Follow-up interviews with willing respondents may also be sought for clarification of questionnaire data.

\section{Third-party study}

Data collection for the third-party research within the insurance and employment sectors will principally be undertaken through a national survey. For the insurance sector, which is relatively contained in terms of number of organizations (approximately 40 registered life insurance companies and approximately 160 insurance companies within the general insurance industry), full population data will be sought. In the employment sector, which is much larger and more diverse, approximately 2000 employers will be surveyed nationally comprising a mix of small, medium, and large employers across the sector.

A combination of quantitative and qualitative data will be collected through the national surveys in both the insurance and employment sectors. Data sought will include the frequency and characteristics of cases to date which have had an explicit genetic component, the relevance of genetic risk to deliberations, and the processes through which such cases have been determined, including details of data used to support the decisions made. In addition, data regarding policy, practice, and response to this issue across all levels of these sectors will be sought with a view to determining the legal status of decisionmaking in this area in the light of the existing statutory exemption from disability discrimination.

As much less is known about the position of employers on the use of genetic information, the peak bodies representing 
the employment sector, at the Commonwealth, state, and territory level, will be surveyed to ascertain their policies, if any, in dealing with the use of genetic testing for employment purposes and experiences with genetic risk as an issue in employment. Furthermore, follow-up interviews (a total of 100) will be undertaken in the employment sector involving targeted sampling along predetermined lines (having regard to size, geographical spread, type of industry, etc.) in order to explore in greater depth, awareness of the uses of genetic information in the workplace and attitudes about the use of such information.

\section{Legal system study}

Research into the consumer and third-party sectors will be augmented by research into the Australian legal system to identify and track any cases (whether or not pursued to final determination) involving allegations of genetic discrimination. Relevant data to be sought from the legal system include numbers of individual cases processed involving allegations of genetic discrimination and their outcomes, as well as mechanisms and channels through which such cases have been presented and determined.

Key bodies relevant to these data are state and territory agencies and tribunals responsible, respectively, for the investigation and hearing of discrimination complaints; industrial tribunals at Commonwealth, state, and territory levels (for cases of alleged discrimination arising within an existing employment relationship); as well as Commonwealth, state, and territory ombudsmen. Data will be collected using survey questionnaires, through analysis of files, and, where appropriate, follow-up interview to more fully examine individual cases. The direct data collection from tribunals will be supported by legal database searches as well as searches undertaken through other sources, e.g., employee peak bodies.

\section{Integrated data analysis}

A final stage of data analysis will involve the integration of the three perspectives into a comprehensive overview of genetic discrimination in Australia and an analysis of the implications of all findings for legal, social, and policy contexts. The construction of a range of case studies representing key features in the interaction between individuals, third parties, and the legal system in Australia will be one research outcome which will facilitate the presentation and dissemination of findings.

\section{Expected outcomes}

The anticipated outcomes from this research are numerous: the conceptual dimensions of genetic discrimination will be explored across a range of consumer experiences and genetic risks; the social contexts in which discrimination is reported by consumers will be documented; and a profile of frequency and characteristics of discrimination incidents will be collected, as will responses and outcomes, perceived consequences, and barriers to redress. From insurance and employment sectors, a profile of the frequency and characteristics of genetics-related cases and/or issues will be produced as well as features of current policy and practice in relation to the determination of cases in which genetic risk has played a role. Finally, within the Australian legal framework, documentation and analysis will be forthcoming for all cases to date that have related to genetic discrimination, their outcomes, and features of legal mechanisms through which such cases have been processed. It is anticipated that the data produced from this multifaceted investigation will assist in identifying areas where legal or other reforms are required. In this regard, the study complements the current national inquiry into the protection of human genetic information referred to earlier. Furthermore, this empirical study will contribute significant baseline data for facilitating ongoing assessment of the nature and extent of the problem, as well as for longitudinal evaluation of the impact and effectiveness of any reforms that may be introduced in the future to address the issue.

\section{Conclusion}

Genetic discrimination is an emerging social issue of significance in Australia which will have increasing relevance as the number of available genetic tests increases. These issues will require informed social, legal, and health policy responses in the foreseeable future, and this research offers substantial national benefit through increasing our understanding of the nature, dimensions, and contexts of genetic discrimination in Australia. It is also of significance internationally as it is the most substantial empirical study of its kind to be undertaken to date into genetic discrimination. Through its triangulated design and integrated conceptual framework, this study promises new insights into genetic discrimination: it will advance conceptual understanding of the phenomenon and inform social policy and law-making in human genetics.

\section{Acknowledgments}

This research is funded by the Australian Research Council under its Discovery Projects scheme, for the period 2002-2004 (inclusive).

\section{References}

1. Billings P, Kohn M, de Cuevas M, Beckwith J, Alper J, Natowicz MR. Discrimination as a consequence of genetic testing. Am J Hum Genet 1992;50:476-482.

2. Geller L, Alper J, Billings P, Barash C, Beckwith J, Natowicz M. Individual, family and societal dimensions of genetic discrimination: a case study analysis. Sci Eng Ethics 1996;2:71-88.

3. Lapham E, Kozma C, Weiss J. Genetic discrimination: perspectives of consumers. Science 1996;274:621-624.

4. Low L, King S, Wilkie T. Genetic discrimination in life insurance: empirical evidence from a cross sectional survey of genetic support groups in the United Kingdom. BMJ 1998;317:1632-1635.

5. Taylor S. A case study of genetic discrimination: social work and advocacy in a new context. Aust Soc Work 1998;51:51-57.

6. Barlow-Stewart K, Keays D. Genetic discrimination in Australia. J Law Med 2001;8: $250-262$.

7. Keays D. When is genetic discrimination justified? Monash Bioeth Rev 2000;19:7988 .

8. Media release, August 9, 2000, Attorney-General Daryl Williams and Minister for Health, Michael Wooldridge. The website address for details of the Terms of Reference and other information is http://www.alrc.gov.au/index.html. In November 2001, an Issues Paper was released seeking submissions and a round of public meetings was undertaken. This is to be followed by the release of a Discussion Paper in 
mid-2002. The inquiry is due to report back in March 2003 (the original time-frame of mid-2002 having been extended).

9. Marteau T, Richards M, editors. The troubled helix: social and psychological implications of the new human genetics. Cambridge, England: Cambridge University Press, 1995.

10. Burley J. The genetic revolution and human rights. Oxford, England: Oxford University Press, 1999.
11. Peters T, editor. Genetics: issues of social justice. Cleveland: Pilgrim Press, 1998.

12. Council of Europe. Bioethics Convention on Human Rights and Biomedicine. UNESCO, Universal Declaration on the Human Genome and Human Rights, 1997.

13. McGlennan T. Insurance and genetic information. Association of British Insurers Research Report, 2001:44-45.

14. Disability and Discrimination Act. (Cth) 1992 ss 46 and s 15(4)(b), respectively, and equivalent state and territory legislation. 